\title{
ANÁLISE DOS RISCOS AO BANHO DE MAR NO MUNICÍPIO DE PONTAL DO PARANÁ - PR - TEMPORADA 2003/2004
}

\author{
Angelotti, R.* \& Noernberg, M. A. \\ Universidade Federal do Paraná, Centro de Estudos do Mar, Laboratório de Oceanografia Costeira e \\ Geoprocessamento; Av. Beira Mar s/n. Caixa Postal: 50002. Pontal do Paraná - PR, 83255-000 \\ ${ }^{*}$ Corresponding author: rangelpontal@gmail.com
}

\begin{abstract}
ANGELOTTI, R. \& NOERnBerG, M. A. 2010. Risk analysis of sea bathing in Pontal do Paraná county, PR Season 2003/2004. Braz. J. Aquat. Sci. Technol. 14(1): 65-75. ISSN 1808-7035. This work aims to analyze the features related to bather safety at Pontal do Paraná - PR. The study is concentrated on environmental risks, on bather behavior and spatial distribution of bather rescue. A GIS was structured with information about beaches infrastructure, the permanent and temporary risks, bather's density in each beach, the safeguards houses and rescue statistics. Generally Pontal do Paraná bathers are neglect with their security. Only $54 \%$ of them to bath in patrolled places, $74 \%$ don't ask for the lifeguard's information about the sea condition and 17\% don't observe the sea condition before bather. About the bather capability of swimming was found that $50 \%$ of the bathers don't know to swim. Despite this, $44 \%$ of the bathers go to the sea with the water at level of their thorax or above. This finding may help explain the large amount of rescue. The most part of bathers ignore the environmental risks of sea bathing like: surf zone currents; tides which continually change water depth and current velocities; wind-driven currents, and rip currents. So the hazards during sea bathing happen by an equivocated perception of the beach environment. The GIS show be useful to understand the relationship among the behavior of the bather on the beach, the physics parameters that drive the beach morphodynamic and the available lifeguards patrolling infrastructure.
\end{abstract}

Keywords: Beach Safety, Pontal do Paraná, GIS.

\section{INTRODUÇÃO}

As praias são importantes áreas recreacionais em torno das quais se concentram atividades turísticas e comerciais, envolvendo grande quantia de recursos humanos e financeiros (Hoefel \& Klein, 1998). Principal recurso turístico do litoral do estado do Paraná, as praias arenosas são responsáveis pela atração de milhares de pessoas que, todos os anos, movimentam a economia local durante a temporada de verão. Estes freqüentadores sejam eles turistas de um dia, proprietários de casa ou veranistas, elegeram a praia como seu local de descanso e lazer.

O banho de mar e os esportes aquáticos são atividades bastante populares entre os usuários de praia. A pouca familiaridade com o ambiente praial e/ou a falsa sensação de segurança, faz com que esse visitante desconheça ou subestime os perigos naturais existentes nas praias, bem como a maneira de evitá-los, aumentando a probabilidade de acidentes relacionados ao banho de mar.

Nas praias podem ocorrer perigos permanentes e não permanentes. Os perigos permanentes são aqueles que nunca mudam de lugar e uma vez conhecidos podem ser facilmente evitados. Já os perigos não permanentes são aqueles variáveis e exigem do banhista cuidado e atenção para serem identificados.

As praias paranaenses, apesar de diversos trabalhos acadêmicos terem sido desenvolvidos sob a ótica da ecologia, geologia e morfodinâmica, ainda carecem de trabalhos enfocando a forma de utilização da praia por seus freqüentadores. Este trabalho tem como objetivo avaliar os aspectos relativos à segurança ao banho de mar dos usuários das praias do município de Pontal do Paraná, no litoral do Paraná. O estudo se concentrou nas dimensões dos perigos ambientais, do comportamento dos usuários e da distribuição espacial dos salvamentos de banhistas.

\section{ÁREA DE ESTUDO}

A praia de pontal do Paraná localiza-se entre as

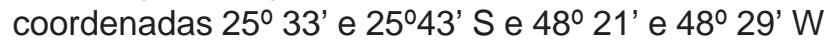
no litoral do Paraná. O município situa-se ao sul do Complexo Estuarino de Paranaguá, na planície costeira da Praia de Leste, compreendendo a parte norte do arco praial existente entre o município de Matinhos e a 
desembocadura sul da baía de Paranaguá. Apresenta uma orla com extensão total de $22,6 \mathrm{~km}$, estando limitada ao norte pela desembocadura do canal feito pelo Departamento Nacional de Obras de Saneamento (canal DNOS) e ao sul pela divisa com o município de Matinhos (Fig. 1).

Toda a extensão da praia de Pontal do Paraná apresenta exposição oceânica, com a dinâmica regida por ondas e correntes de deriva litorânea (Angulo \& Araújo, 1996). Somente num trecho de praia de aproximadamente $3 \mathrm{~km}$ em Pontal do Sul a dinâmica praial é regida por ondas e correntes de maré, isto devido à proximidade da desembocadura do complexo estuarino de Paranaguá. Segundo Bigarella et al. (1978), as praias de Pontal do Paraná apresentam pequena inclinação ( $2^{\circ}$ a $6^{\circ}$ ) e o material que as compõe é de domínio quase que absoluto de grãos de quartzo com granulação relativamente uniforme, constituída predominantemente de areia fina a média.

Com relação ao clima de ondas, dados obtidos entre os meses de agosto e dezembro de 1982 (Portobrás, 1983), através de um ondógrafo de superfície instalado entre o balneário Praia de Leste e a llha de Currais, em local de profundidade aproximada de $12 \mathrm{~m}$, mostraram a existência de dois trens de ondas preferenciais, provenientes das direções $\mathrm{N} 74^{\circ}$ e $\mathrm{N} 174^{\circ}$ (direções ENE e SSE/SE, respectivamente), sendo que as ondas de maior altura são do quadrante SE. A altura máxima registrada foi de 2,35 m em agosto, e 3,95 m em setembro de 1982. O período médio observado variou entre 16,53 e 10,73 segundos.

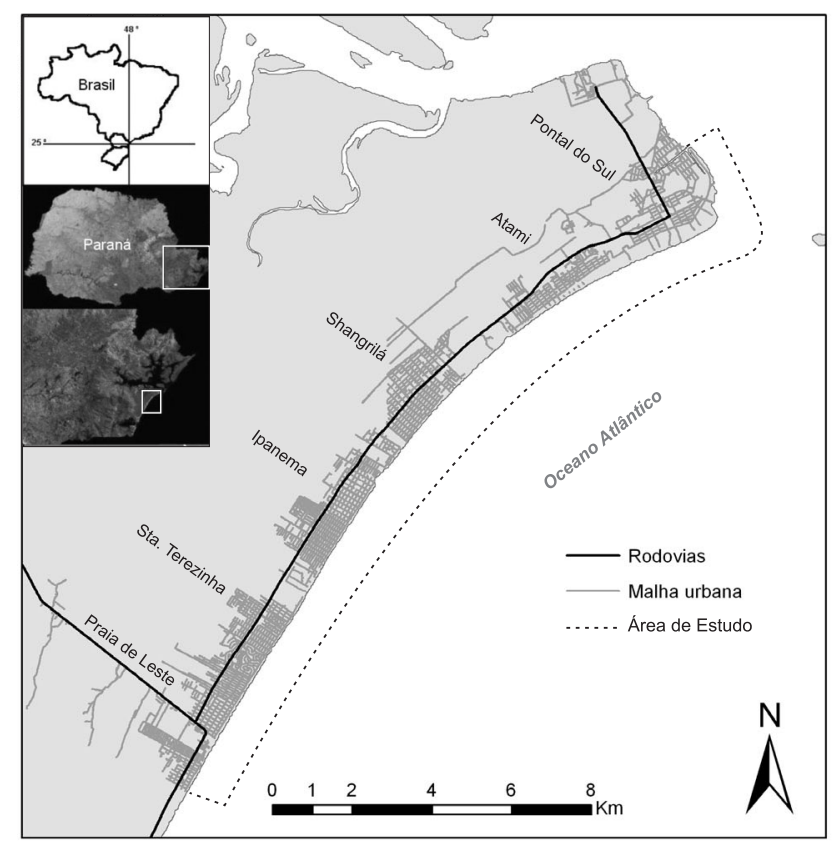

Figura 1. Localização do município de Pontal do Paraná e principais balneários.
O município de Pontal do Paraná possui uma população de 14.323 habitantes e pode ser classificado, juntamente com Matinhos e Guaratuba, na classe dos municípios praiano-turísticos (Estades, 2003). Estima-se que no ano de 2003 os municípios praianos do Paraná receberam na temporada cerca de 1,5 milhão de turistas, dos quais aproximadamente $1 / 3$ foram a Pontal do Paraná. Se este dado estiver próximo da realidade, pode-se afirmar que o município recebe cerca de 500.000 pessoas na temporada de verão, aumentando sua população em 35 vezes. (Estades, 2003) Esta população flutuante é grande durante todo o verão, intensificando-se nas festas de final de ano e no carnaval.

Ao se fazer uma análise do histórico da ocupação recente, verifica-se que antes da construção da rodovia PR-412 as construções predominantes eram casas e ranchos de pesca, concentrados em pequenos agrupamentos. As principais atividades econômicas, até meados da década de 70 eram a pesca artesanal e, principalmente, as lavouras de subsistência, tendo a banana e a mandioca como principais produtos.

Atualmente a Microrregião do Litoral Paranaense, onde Pontal do Paraná insere-se, é caracterizada como uma das mais urbanizadas do Estado do Paraná. Segundo o Censo Demográfico 2000 (IBGE, 2001) 88\% da população litorânea, de 236 mil habitantes, residiam em áreas urbanas. O litoral paranaense apresenta ainda grandes taxas de crescimento populacional. Entre os anos 1991 e 2000, a taxa de crescimento anual foi de $3,39 \%$, enquanto a taxa de crescimento da população brasileira foi de $1,6 \%$ ao ano. No município de Pontal do Paraná, este crescimento é ainda maior, apresentando taxas anuais superiores a $10 \%$ para o período entre 1991 - 2000. Neste município, assim como em toda a Microrregião do Litoral Paranaense, se confirma a predominância da população na área urbana, especialmente pelo fato da mesma ter sua principal vocação econômica destinada ao turismo, abrangendo um expressivo número de balneários para veranistas.

\section{MATERIAL E MÉTODOS}

\section{Perfil dos Usuários de Praia}

Foram aplicados questionários ao público usuário das praias, com o intuito de avaliar o conhecimento e o comportamento dos banhistas no tocante aos perigos naturais da praia (Tabela 1), bem como o perfil sócio-econômico desses usuários. As entrevistas foram realizadas nos dias 27/12/2003, 30/12/2003, 03/01/2004 e 17/01/2004.

Os questionários foram aplicados simultaneamente nos principais balneários do município: Pontal 
do Sul, Atami, Shangrilá, Ipanema, Santa Terezinha e Praia de Leste. Os entrevistados foram escolhidos aleatoriamente, sendo entrevistados somente usuários com mais de 15 anos de idade. Usuários de idade inferior foram contemplados nas entrevistas respondidas pelos pais ou responsáveis. Ao todo foram aplicados 437 questionários. Os dados obtidos nas entrevistas foram inseridos, processados e analisados no aplicativo de banco de dados Microsoft Access.

Nas entrevistas realizadas foram consideradas, além da população registrada pelos órgãos oficiais, outras categorias populacionais que influem e demandam por infra-estrutura urbana do município, como:

1. população com residência fixa - também denominados de moradores locais;

2. população com residência temporária - especialmente aposentados, os quais têm residência em outros municípios do estado, mas que em diferentes períodos do ano residem por alguns meses no município;

3. população de final de semana - são aqueles que sistematicamente aportam no município para o descanso semanal ou mesmo para feriados prolongados;

4. população flutuante - são aqueles que vão aos balneários principalmente na época das férias de verão.

\section{Sistema de Informações Geográficas}

Um Sistema de Informações Geográficas (SIG) foi estruturado utilizando a plataforma SPANS (PCI),
Tabela 1. Estrutura do roteiro padrão utilizado para a realização das entrevistas com o público usuário das praias de Pontal do Paraná.

\begin{tabular}{ll}
\hline Dados sociais & Conhecimento da Praia \\
\hline Sexo & Familiaridade \\
Procedência & Freqüência de uso \\
Rendimento Familiar & Freqüência com que toma banho de \\
& mar \\
Grau de escolaridade & Profundidade que toma banho de mar \\
Faixa etária & Sinais de perigo potenciais ao banho \\
de mar & Cuidados tomados ao entrar no mar \\
Habilidade de natação & Grau de perigo que o mar oferece \\
Envolvimento em acidentes de banho & $\begin{array}{l}\text { Cuidados tomados em relação aos } \\
\text { filhos }\end{array}$ \\
\hline \hline
\end{tabular}

onde foi utilizada uma base de dados sócio-ambientais previamente estruturada (Noernberg et al., 1997, 2006). Constavam dessa base os dados de drenagem, rodovias, altimetria, divisão política do município e arruamento do município de Pontal do Paraná. Um traçado atualizado da linha de costa foi obtido através de levantamento de campo pelo método de caminhamento com uso de um GPS (Global Positioning System), marca Garmin, modelo E-trex, com erro médio de $10 \mathrm{~m}$. O datum horizontal utilizado foi o WGS84 e a estruturação do SIG é apresentada na Figura 2.

Também utilizando um equipamento de GPS, foram mapeadas as posições dos Postos de Guardavidas do Corpo de Bombeiros nos balneários de Pontal do Paraná. Informações sobre os recursos humanos, características do patrulhamento das praias e equipamentos utilizados nos postos foram levantadas através de entrevistas com os oficiais do Corpo de Bombeiros. Posteriormente, as coordenadas geográficas e os nomes dos postos foram inseridos no SIG.

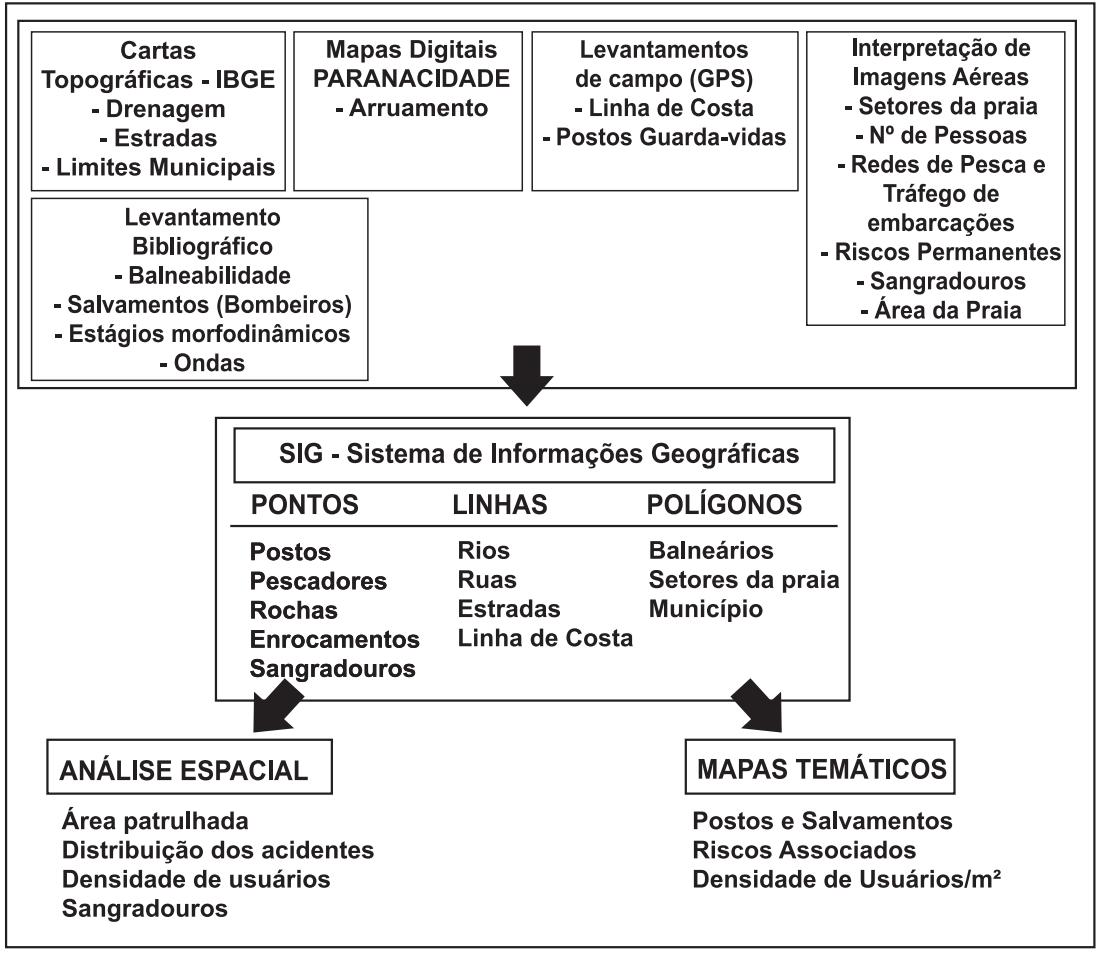

Figura 2. Estrutura do Sistema de Informações Geográficas. 
Tabela 2. Número de usuários em cada balneário (11:30h do dia 23/02/2004)

\begin{tabular}{lcc}
\hline \hline Balneário & Número de pessoas na praia & $\%$ \\
\hline Pontal do Sul & 1177 & 13,3 \\
Atami & 215 & 2,4 \\
Shangrilá & 1607 & 18,2 \\
Ipanema & 2163 & 24,5 \\
Santa Terezinha & 1977 & 22,3 \\
Praia de Leste & 1701 & 19,2 \\
TOTAL & 8840 & 100 \\
\hline \hline
\end{tabular}

Objetivando uma análise espacial da distribuição dos salvamentos, também foram integrados no SIG dados relativos a salvamentos e mortes por afogamento registrados pelos guarda-vidas, levantados junto ao Comando Geral do Corpo de Bombeiros do Estado do Paraná. Foram analisadas as informações referentes às temporadas: 1997/1998, 1998/1999, 1999/2000, 2000/2001, 20001/2002, 2002/2003 e 2003/2004.

Através de análise espacial no SIG, foi obtida a extensão de praia em cada um dos seis balneários analisados, assim como o número de postos de guarda-vidas do corpo de bombeiros. Considerando que cada posto do corpo de bombeiros patrulha uma área de cem metros para cada lado, foi calculada a distância patruIhada em cada balneário e a porcentagem da praia coberta pelos guarda-vidas.

\section{Densidade de usuários na praia}

Para estimar a densidade de usuários na praia foi realizado um sobrevôo ao longo dos balneários de Pontal do Paraná. O sobrevôo foi no dia 23 de fevereiro de 2004, segunda-feira de carnaval, às 11:30 da manhã, e com uma câmera de vídeo obteve-se uma imagem contínua de toda a faixa de praia de Pontal do Paraná. O dia e o horário da filmagem aérea foram escolhidos por serem representativos de um momento de pico na quantidade de pessoas presentes na praia. Esta filmagem foi convertida para o formato digital utilizando o software Adobe Premiere.

Através do reconhecimento de pontos notáveis do terreno sobre a imagem, a faixa de praia foi separada em setores, sendo então contado o número de pessoas presentes em cada setor. Considerando a largura média da faixa de praia em 50 metros, estes setores foram digitalizados no SIG e em seguida foi estimada a densidade de usuários de praia por metro quadrado no momento do sobrevôo. De acordo com a amplitude dos dados, foi estabelecida uma escala para representar graficamente a densidade de usuários por metro quadrado em cada setor da praia. A partir disso, foram gerados mapas que permitiram visualizar os locais de maior densidade de usuários para o momento da aquisição do vídeo.

\section{Locais de Risco ao Banho de Mar}

Através da interpretação da filmagem aérea realizada e de confirmação através de saídas de campo, foram mapeados os locais onde existem riscos permanentes, ou seja, aqueles que nunca mudam de lugar, sendo eles: áreas de desembocadura de rios e baías, e as áreas com obstáculos (costões rochosos, enrocamentos e rochas submersas).

Locais com problemas de balneabilidade foram identificados através da análise dos boletins emitidos pelo IAP (Instituto Ambiental do Paraná) durante a temporada 2003/2004. Foram mapeados também os locais de tráfego de embarcações e áreas identificadas como sendo freqüentemente utilizados para a pesca artesanal. Também foram obtidas da filmagem aérea as localizações dos sangradouros (pequenos córregos intermitentes que deságuam na praia).

\section{RESULTADOS E DISCUSSÃO}

\section{Perfil sócio-econômico e comportamental dos usuários da praia}

Quanto à procedência dos usuários da praia de Pontal do Paraná, quase 92\% são paranaenses, sendo que destes, $70 \%$ são de Curitiba e Região metropolitana. A Figura 3 mostra o rendimento familiar mensal informado pelos entrevistados.

O balneário Ipanema concentra a maior parte dos usuários considerados de baixa renda, e o balneário Atami os de faixa de renda mais elevada. É importante salientar que o balneário Atami é praticamente um condomínio fechado com casas de veraneio de alto padrão.

Pessoas na faixa etária entre 15 e 40 anos representam mais de $75 \%$ dos freqüentadores. Pelo grau de escolaridade verifica-se que os freqüentadores são pessoas na maioria alfabetizados com certo grau de 


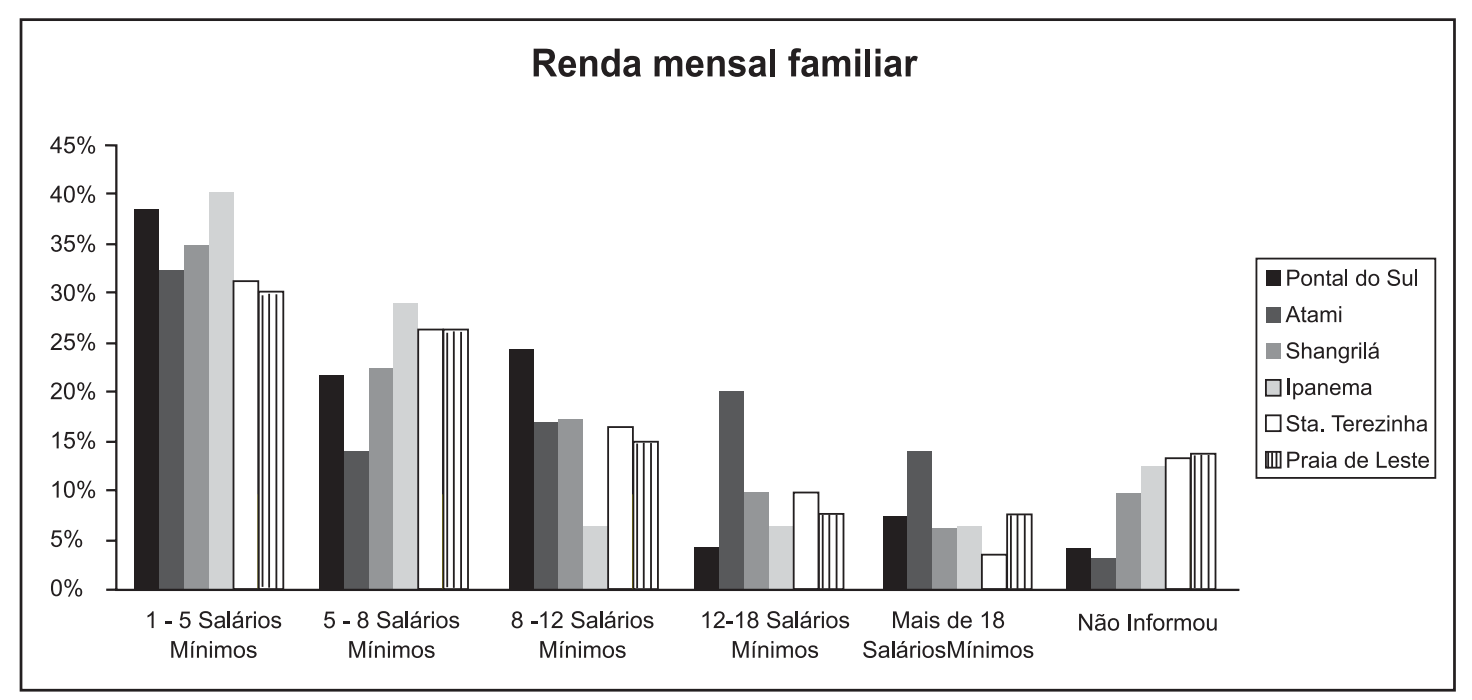

Figura 3. Renda familiar dos usuários dos balneários de Pontal do Paraná.

conhecimento, com renda familiar entre 1 e 8 salários mínimos.

A distribuição dos usuários entre os balneários de Pontal do Paraná é praticamente homogênea, com exceção do balneário Atami que possui número de usuários bem inferior em relação aos demais balneários. 0 Balneário Ipanema é o mais freqüentado com $24,5 \%$ dos usuários dos balneários no momento do sobrevôo (Tabela 2).

No que se refere à habilidade de natação, os dados obtidos nas entrevistas mostram que $50 \%$ dos entrevistados não sabem nadar. Os balneários com maior número de usuários que não sabem nadar são: Praia de Leste (64\%), Ipanema (57\%) e Santa Terezinha (54\%). Atami é o balneário onde a maior porcentagem de usuários diz saber nadar (73\% das respostas). $8,31 \%$ dos entrevistados já se envolveram em acidente relacionado ao banho de mar, sendo que $2,1 \%$ se envolveram em acidente na mesma praia onde foram entrevistados e 6\% já se envolveram em acidente em outra praia.

O questionário aplicado também continha uma pergunta formulada com o intuito de saber até que altura do corpo os entrevistados entram no mar. A porcen- tagem de respostas a essa pergunta se distribui da seguinte maneira: $9 \%$ dos entrevistados entram no mar com água até o joelho, $47 \%$ entram com água até a cintura, $29 \%$ com água até o peito, $8 \%$ com água até o pescoço e 7\% com água superior à altura do corpo. Analisando as respostas agrupadas por sexo verificase que, dos entrevistados que entram no mar com água no máximo até a altura da cintura, $65,8 \%$ são mulheres. Os que entram no mar com água superior à altura do peito $66 \%$ são homens.

A presença de buracos ou correntes é o primeiro sinal, para $54 \%$ dos entrevistados, de que o local a ser usado para banho de mar oferece perigo. Já a altura de ondas é o primeiro sinal de que o mar oferece perigo para $20 \%$ dos entrevistados. Apenas $20 \%$ dos entrevistados reconhecem nas placas de sinalização colocadas pelos Guarda-vidas do Corpo de Bombeiros o primeiro sinal de perigo no local escolhido para o banho de mar.

O balneário onde os entrevistados menos prestam atenção nas bandeiras de sinalização dos Guarda-vidas é Shangrilá. Dos que acham que a bandeira é o primeiro sinal de perigo, apenas 3,5\% estão nesse balneário. No balneário Atami está a maior quantidade

Tabela 3. Comprimento da praia e distância patrulhada por posto de guarda-vidas em cada balneário.

\begin{tabular}{lcccc}
\hline \hline Balneário & $\begin{array}{c}\mathrm{N}^{\circ} \text { de } \\
\text { Postos }\end{array}$ & $\begin{array}{c}\text { Comprimento } \\
\text { da praia }(\mathrm{m})\end{array}$ & $\begin{array}{c}\text { Distância } \\
\text { patrulhada }(\mathrm{m})\end{array}$ & $\begin{array}{c}\% \text { do } \\
\text { balneário } \\
\text { patrulhado }\end{array}$ \\
\hline Pontal do Sul & 3 & $4.700 \mathrm{~m}$ & $600 \mathrm{~m}$ & $12,8 \%$ \\
Atami & 1 & $3.000 \mathrm{~m}$ & $200 \mathrm{~m}$ & $6,6 \%$ \\
Shangrilá & 7 & $3.200 \mathrm{~m}$ & $1.400 \mathrm{~m}$ & $43,7 \%$ \\
Ipanema & 6 & $3.300 \mathrm{~m}$ & $1.200 \mathrm{~m}$ & $36,3 \%$ \\
Santa Terezinha & 8 & $2.700 \mathrm{~m}$ & $1.600 \mathrm{~m}$ & $59,2 \%$ \\
Praia de Leste & 7 & $2.300 \mathrm{~m}$ & $1.400 \mathrm{~m}$ & $60,8 \%$ \\
\hline \hline
\end{tabular}


dos entrevistados que acham a bandeira de sinalização o primeiro sinal de perigo no local escolhido para o banho de mar (25,8\%).

Dos entrevistados que responderam que a presença de buracos e correntes é o primeiro sinal de perigo observado, apenas 7,2\% encontram-se no balneário Atami, seguido por $12 \%$ no balneário Santa Terezinha.

Foi avaliado o grau de perigo que os usuários acham que a praia que freqüentam oferece. $19 \%$ dos entrevistados acham que a praia não é perigosa, $20 \%$ acham que sim, ela é perigosa; e $62 \%$ acham que se respeitada, ela não é perigosa.

O local de maior concentração de usuários é a parte central do balneário de Ipanema. Somente nesse balneário, em horário de pico de movimento foram contadas 2.163 pessoas, representando $24,5 \%$ do total de usuários presentes na praia de Pontal do Paraná no horário da contagem.

Verificou-se através das saídas de campo, que os guarda-vidas em sua maioria, estão preparados para reconhecer as correntes de retorno. Diariamente eles identificam as correntes na sua área de patrulhamento e demarcam sua posição com uma placa indicando perigo. O problema é que, conforme constatado nas entrevistas, apenas $20 \%$ dos entrevistados costumam prestar atenção nesta sinalização. Durante a temporada foram raros os locais identificados com placas onde não havia banhistas.

\section{Estrutura de patrulhamento e acidentes}

Para garantir a segurança dos banhistas e usuários, torna-se necessário um serviço de patrulhamento, devendo este ser feito por profissionais habilitados a executar atividades de busca, salvamento aquático e recuperação de afogados. Este trabalho de patrulhamento das praias paranaenses é de responsabilidade do Corpo de Bombeiros da Polícia Militar do Paraná.

Para a chamada "Operação Verão" são utilizados, além do efetivo existente no $2^{\circ}$ Sub-grupamento de Bombeiros Independente de Paranaguá, recursos humanos de outros quartéis do estado, os quais preenchem as várias funções decorrentes das atividades desenvolvidas.

Na temporada $2003 / 2004$ os postos de guardavidas foram ativados no dia 20/12/2003, funcionando diariamente das 8:00h às 19:30h nos dias de semana e das 8:00 às 20:00h nos finais de semana e feriados. O encerramento da operação verão se deu no dia 29/ 02/2004. Portanto, os postos permaneceram funcionando durante 72 dias. Os guarda-vidas são divididos em duas equipes, trabalhando um dia pelo período da manhã, e outro dia no período da tarde, sendo que no dia que trabalhará de tarde ele realiza pela manhã a práti- ca de condicionamento aquático. Cada posto é patruIhado por dois guarda-vidas em cada turno de trabalho. Os guarda-vidas em Pontal do Paraná não dispunham, na temporada 2003/2004, de estrutura adequada para a realização do seu trabalho. Não existem postos construídos de maneira permanente, fazendo com que os guarda-vidas dependam da boa vontade de moradores para a utilização de sanitários e fornecimento de água potável. Além disso, os guarda-vidas ficam suscetíveis às intempéries, sem ter onde se abrigar em caso de tempestade ou mau tempo. Os postos poderiam ser construídos de forma que a estrutura possa ser utilizada como mirante para uma melhor observação da praia, além de possuir banheiro, chuveiro e local adequado para guardar os materiais de salvamento.

Lugares onde a linha de costa apresenta grandes extensões de restinga e/ou sofre processos erosivos, como no caso do balneário Pontal do Sul (Angulo, 1993), torna-se inviável a construção de postos fixos de alvenaria. Nestes locais a solução seria a colocação de postos móveis, permitindo sua mobilidade em caso de erosão.

Durante toda a Operação Verão o patrulhamento é realizado com o mesmo efetivo e equipamentos. Uma medida que poderia tornar o sistema de patrulhamento mais eficiente seria a diversificação do esforço de acordo com a condição do mar e do número de pessoas presentes nas praias, a exemplo do modelo desenvolvido na Austrália. Neste país existe uma classificação de risco público em três níveis, onde a alocação de equipamentos é diferenciada em função do número de usuários de uma praia e o seu grau de periculosidade (Short \& Hogan, 1990).

A extensão total de orla dos balneários de Pontal do Paraná a ser atendida pelo Corpo de Bombeiros é de 19,2 km, estando os 3,4 km restantes situados na área desabitada entre Ipanema e Santa Terezinha e entre Atami e Shangrilá. Considerando que cada posto patrulha uma faixa de praia de 100 metros para cada lado, estima-se que apenas $28,3 \%$ da extensão total da orla do município é patrulhada (Tabela 3).

O posto que mais realizou salvamentos foi o de Ipanema II. $\mathrm{Na}$ área patrulhada por este posto foram retiradas da água 83 pessoas na temporada 2001/2002. Em todas as temporadas analisadas este posto registrou os maiores valores. Dos 2702 salvamentos realizados pelo Corpo de Bombeiros entre os anos 1998 e 2004, 30\% ocorreram em Ipanema, 26\% em Praia de Leste, 23\% em Santa Terezinha, 28\% em Shangrilá, $4 \%$ em Pontal do Sul e menos de 1\% em Atami.

É interessante notar que todas as cinco mortes por afogamento ocorridas em Pontal do Paraná nas temporadas 2002/2003 e 2003/2004 aconteceram na região de entreposto, onde não há patrulhamento. Nes- 


\section{Salvamentos por balneário}

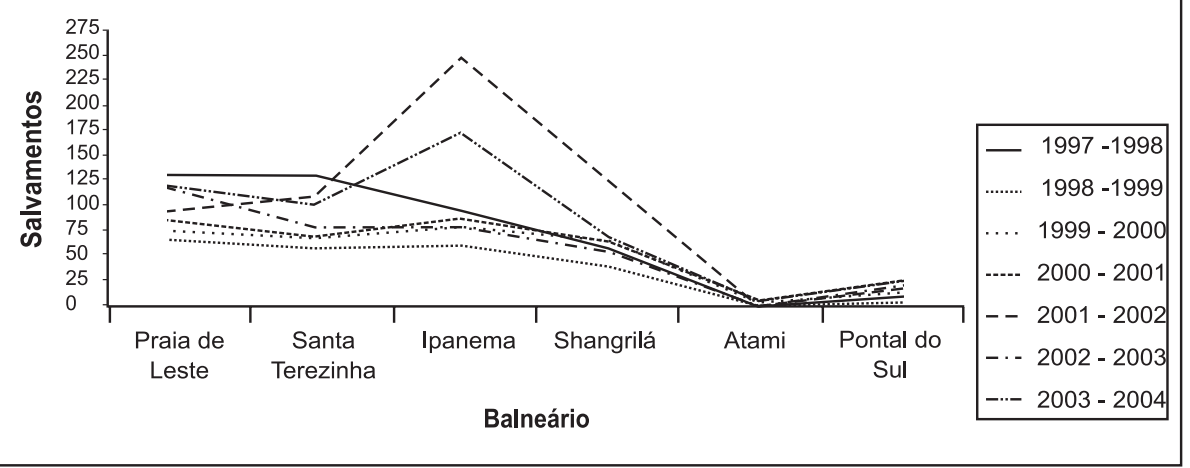

Figura 4. Quantidade total de salvamentos por balneário entre as temporadas 1997/1998 e 2003/2004.

tes locais a segurança depende exclusivamente do usuário.

Ainda com relação aos óbitos, verificou-se que na pré-temporada 2003, em menos de um mês, vieram a falecer cinco pessoas por afogamento, todas entre 0 balneário Shangrilá e Ipanema. Quatro desses acidentes ocorreram em um mesmo final de semana. Através da Análise das cartas sinóticas publicadas pela Marinha do Brasil, foi possível verificar a passagem de um sistema frontal pelo litoral da região nos dias anteriores aos dos acidentes, causando grande agitação marítima na costa, o que aumentou a periculosidade do banho de mar.

O número de acidentes fatais em apenas um mês na pré-temporada 2003 foi igual à soma dos óbitos de duas temporadas (2002/2003 e 2003/2004).

Com relação à quantidade de salvamentos, existe uma grande diferença entre os balneários (Fig. 4). Isso parece estar relacionado mais com a quantidade de usuários e com seu perfil comportamental do que com as características físicas das praias, uma vez que, com exceção de Pontal do Sul que está numa área de desembocadura, a praia de Pontal do Paraná não apresenta grandes variações morfodinâmicas entre seus balneários. Porém, ainda não é possível afirmar se existe atualmente esta diferença, tornando-se necessários estudos mais detalhados dessas condições.

De acordo com informações do Corpo de Bombeiros, muitos óbitos acontecem no período noturno, o que revela uma imprudência e/ou falta de conhecimento de determinados usuários em relação aos riscos existentes no mar.

Um indicativo sobre o porquê das diferenças na quantidade de salvamentos realizados nos balneários pode ser encontrado no fato de que a percepção do ambiente praial varia para cada tipo de usuário. Polinari (2000), classifica os freqüentadores das praias de Pontal do Paraná, definindo para isto o conceito de Nicho Signomônico (NS), que seriam grupos de pessoas que percebem, utilizam e interagem com o ambiente de for- ma semelhante, criando o que se chamaria de nichos de consenso.

Apesar do ambiente praial, durante a temporada de verão, parecer relativamente homogêneo com relação ao público usuário, Polinari (2000) comprova que a interação entre os diferentes NS acaba criando áreas geográficas ou territórios na praia, onde haverá a predominância de determinado NS. Os principais grupos identificados em Pontal do Paraná são:

NS praia-de-família: grupo composto por famílias de veranistas, que possuem segunda residência no município. Na praia, caracterizam-se por uma família sob o guarda sol, mantendo uma distância razoável do guarda-sol do vizinho. Os adultos raramente tomam banho de mar, mas ficam observando as crianças, que o fazem com freqüência. Primam pela tranqüilidade da praia, utilizada como local de descanso e contemplação. Fazem da faixa de areia a extensão do quintal de suas casas, não gostando da presença de outros NS. Polinari (2000) identifica como exemplo de local predominante deste NS a praia de Atami e parte de Pontal do Sul.

NS sátiros-lúdicos ou farofeiros: fazem parte desse grupo pessoas normalmente de menor poder aquisitivo, que permanecem no município apenas um ou poucos dias, chegando muitas vezes através de ônibus de excursão. Também alugam casas para grupos grandes por alguns dias. Devido ao dinheiro escasso e/ou ao menor tempo livre, passam muito tempo na praia, querendo aproveitar ao máximo. Gostam de ficar em grupos grandes na areia, divertindo-se com brincadeiras, jogos e com o banho de mar, considerado indispensável por este grupo. São chamados farofeiros pelo NS praia-de-família, porque comumente trazem seu alimento de casa, consumindo-o na própria praia. Identificase como exemplo de local de predominância desse NS, o acesso principal da praia em Pontal do Sul.

NS festeiros-urbanos: grupo onde predominam jovens que gostam da praia pela badalação, festas e paqueras. Normalmente ficam ao redor de carros com 
som alto, consomem bebidas alcoólicas em grandes quantidades e concentram-se nos locais onde há agitação (barzinhos). O local predominante deste NS em Pontal do Paraná é o balneário de Ipanema.

A predominância da visão de determinado nicho signomônico, através de um processo histórico, irá criar instintivamente estratégias de atração de NS que Ihes são convenientes e de repulsão dos que não o são. Como exemplo, temos o balneário de Pontal do Sul, onde o NS dominante é o praia-de-família. A valorização da tranqüilidade, característica desse NS, é notada pela quase ausência de agitação noturna. Isto faz com que o NS festeiros-urbanos não sejam atraídos para este balneário. Comumente a visão dominante acaba passando à esfera das políticas públicas, fazendo, por exemplo, com que as leis de zoneamento não permitam a construção de bares e casas noturnas em Pontal do Sul, o que poderia interferir no sossego do NS praia-de-família.

Observações em campo sugerem que os locais com maior número de acidentes são os que concentram, de acordo com Polinari (2000), os nichos signomônicos sátiros-lúdicos e festeiros-urbanos. Porém essa relação entre comportamento dos usuários e acidentes precisa ser mais bem investigada.

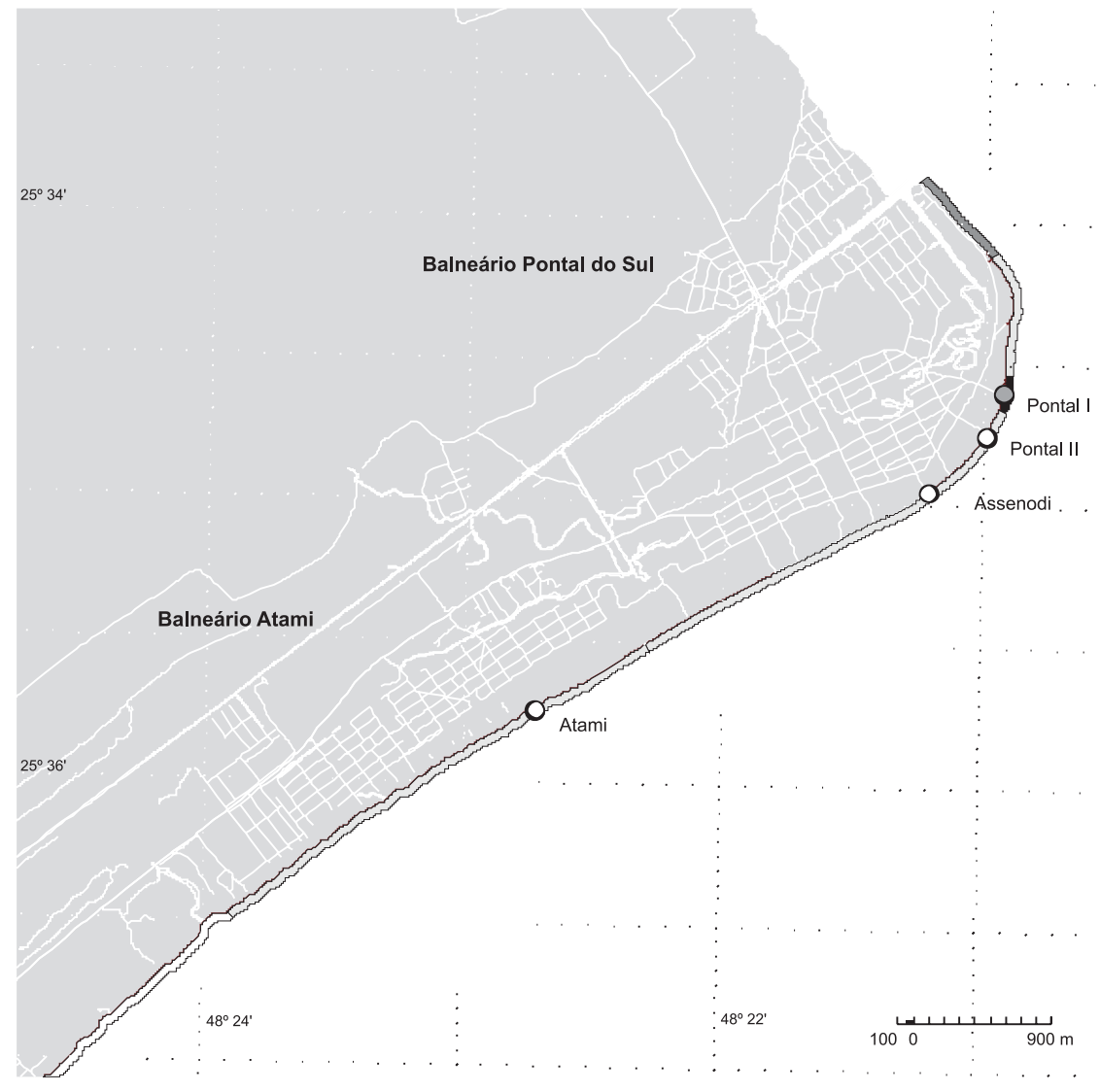

Perigos Permanentes e Não Permanentes

A seguir são apresentados os principais perigos encontrados nas praias de Pontal do Paraná.

\section{Perigos permanentes}

Enrocamento presente no extremo norte do balneário Pontal do Sul, na desembocadura do Canal DNOS, onde ocorre também um intenso tráfego de embarcações. Este mesmo local encontra-se na desembocadura da baía de Paranaguá, onde existem canais na zona de arrebentação, que são dominados por correntes de maré.

\section{Perigos não permanentes}

A desembocadura do rio Olho dágua em Ipanema e a do canal DNOS em Pontal do Sul, apresentaram condição imprópria para banho durante quase toda a temporada, de acordo com os dados do Instituto Ambiental do Paraná. Com relação a animais marinhos perigosos, durante a temporada 2003/2004 foram observados exemplares da caravela Physalia physalis e foram relatados, pelos postos de saúde, acidentes causados por este organismo. Correntes de maré estão associadas à desembocadura da baía de Paranaguá, em Pontal do Sul, as quais podem arrastar pessoas desavisadas.

Figura 5. Mapa temático dos balneários de Atami e Pontal do Sul, mostrando a média de salvamentos por posto, densidade de usuários $/ \mathrm{m}^{2}$ e riscos associados às praias. 
Apesar de não haverem dados registrados, os guarda-vidas afirmam, que as correntes de retorno estão associadas à grande parte dos acidentes. No Estado de Santa Catarina o projeto Segurança nas Praias identificou que mais de $90 \%$ dos acidentes estão relacionados à ocorrência de correntes de retorno de intensidade moderada à forte (Klein et al., 2003). Nas praias australianas Short \& Hogan (1990) identificaram que: $95 \%$ dos salvamentos são realizados em correntes de retorno, e que $95 \%$ dos turistas não sabem reconhecer uma corrente de retorno.

No trabalho de Noernberg (2001), são identificadas intensas correntes de retorno atuando após a passagem de um sistema frontal na praia de Pontal do Paraná, indicando que este fator é importante para a região.

\section{Mapas temáticos}

Visando facilitar a interpretação visual das informações integradas em SIG, foram confeccionados diversos mapas temáticos contendo: a malha urbana do município (ruas e rodovias), drenagem, riscos associados às praias, postos de guarda-vidas, média dos salvamentos registrados em cada um dos postos entre 1997 e 2004 e a quantidade de usuários presente na praia em um horário de grande intensidade de uso (Figuras 5,6 e 7 ).

\section{CONSIDERAÇÕES FINAIS}

Os usuários de praia em Pontal do Paraná, no geral, descuidam bastante da sua segurança. Apenas $54 \%$ dos entrevistados dizem tomar banho somente em locais patrulhados por guarda-vidas, $79 \%$ não se informa com os guarda-vidas sobre as condições para o banho de mar e 17\% não observa o mar antes de entrar na água. No que se refere à habilidade de natação, $50 \%$ dos entrevistados não sabem nadar. Apesar da grande quantidade de usuários que dizem não saber nadar, $44 \%$ das pessoas banham-se com água batendo na altura do peito ou acima. Esse dado pode ajudar a explicar a grande quantidade de salvamentos efetuados, pois se a pessoa não sabe nadar e entra com água pela altura do peito, a chance dela ser arrastada por uma corrente de retorno sem conseguir escapar é bastante grande.

Como nenhuma campanha de prevenção de acidentes foi realizada nos últimos anos e também nenhuma mudança no esquema de patrulhamento do

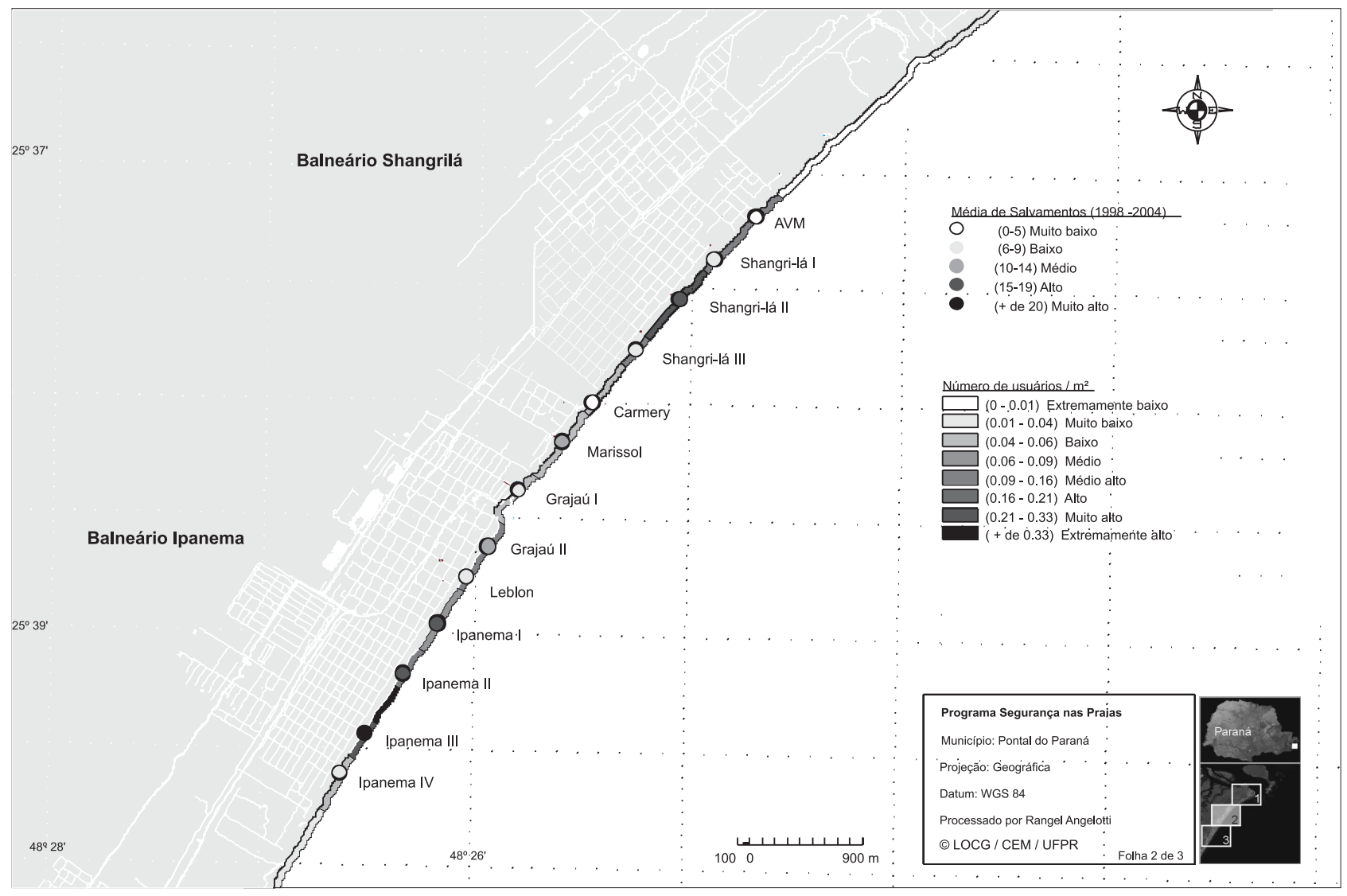

Figura 6. Mapa temático dos balneários de Shangrilá e Ipanema, mostrando a média de salvamentos por posto, densidade de usuários $/ \mathrm{m}^{2}$ e riscos associados às praias. 


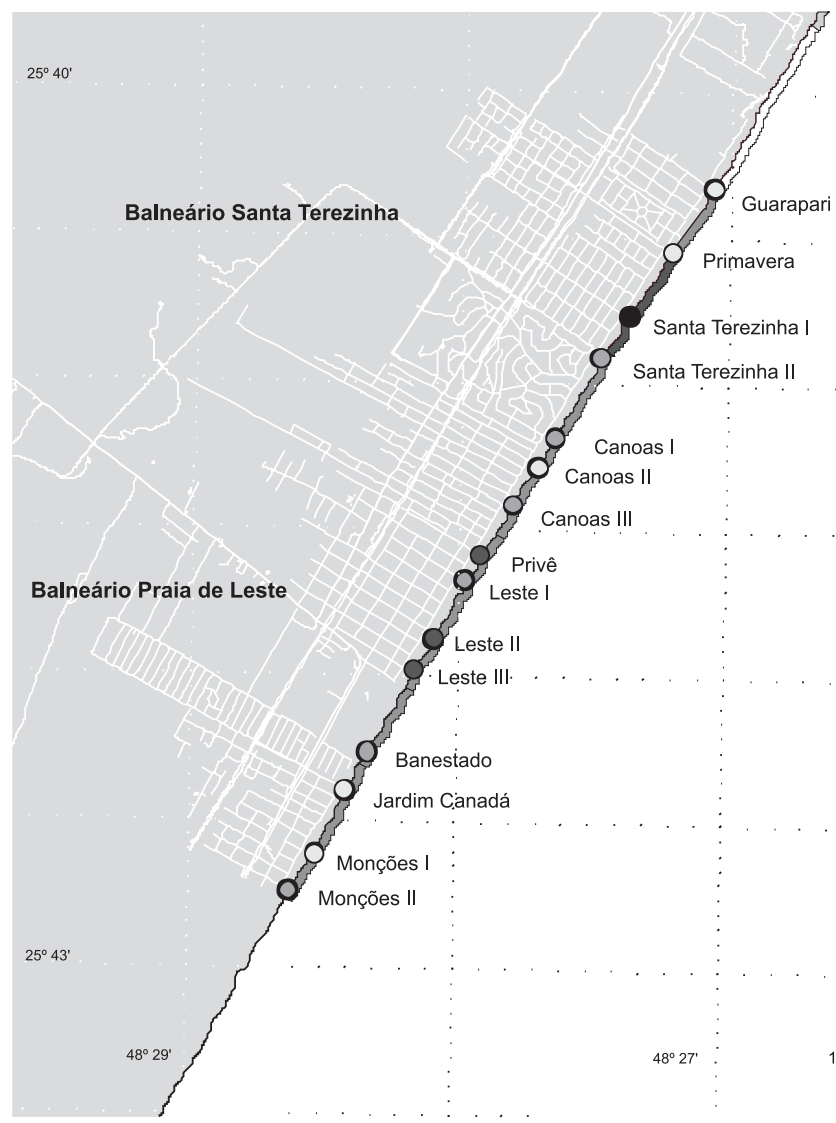

Figura 7. Mapa temático dos balneários de Santa Terezinha densidade de usuários $/ \mathrm{m}^{2}$ e riscos associados às praias.

Corpo de Bombeiros foi feita, a diferença no número total de salvamentos entre as temporadas provavelmente se deva a fatores dinâmicos como: agitação do mar, número de pessoas presentes na praia durante determinada temporada e fatores meteorológicos, como temporadas com período muito grande de chuvas, o que acaba afastando as pessoas da praia.

Apesar de não existirem dados, é provável que nas praias paranaenses seja grande a porcentagem de usuários que não fazem idéia do que seja uma corrente de retorno. Desta forma, torna-se importante efetuar campanhas de divulgação para a população a respeito desse e dos demais perigos associados às praias.

Desta forma, pode-se dizer que os acidentes durante o banho de mar ocorrem mais por uma percepção equivocada do ambiente praial e também pelos aspectos comportamentais do usuário do que por falha ou despreparo do Corpo de Bombeiros.

\section{AGRADECIMENTOS}

Os autores agradecem à Fundação Araucária (Convênio 016/2005, Protocolo 5790) e à Prefeitura Municipal de Pontal do Paraná pelo apoio financeiro.

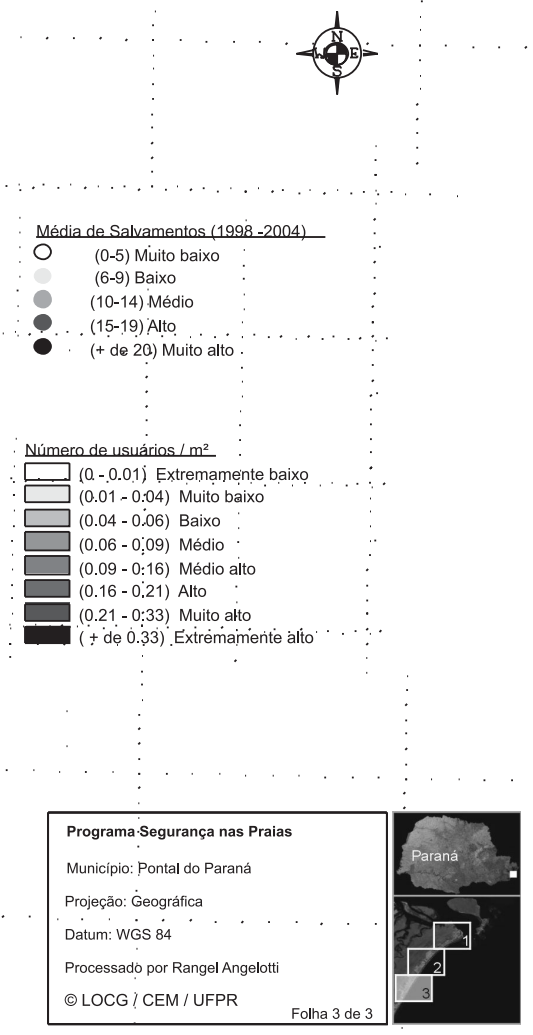

e Praia de Leste, mostrando a média de salvamentos por posto,

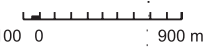

\section{REFERÊNCIAS}

Angulo, R.J. 1993. A ocupação urbana no litoral paranaense e as variações da linha de costa. Boletim Paranaense Geociências. 41: 73-81.

Angulo, R.J.; Araújo, A.D. 1996. Classificação da costa paranaense com base na sua dinâmica, como subsídio à ocupação da orla litorânea. Boletim Paranaense de Geociências. 44: 7-17.

Bigarella, J.J.; Becker R.D.; Matos D.J.; Werner A. 1978. A Serra do Mar e a porção oriental do Estado do Paraná. Um problema de segurança ambiental e nacional: contribuição à geografia, geologia e ecologia regional. 1aㅡ Edição. SEPL-ADEA, Curitiba, 248p.

Estades, N.P. 2003. Litoral do Paraná: entre a riqueza natural e a pobreza social. Desenvolvimento e meio ambiente. 8: 25-41.

Hoefel, F.G.; Klein, A.H. 1998. Beach safety issue at oceanic beaches of central northern coast of Santa Catarina, Brazil: Magnitude and Nature. Journal of Coastal Research. 26:8-11.

IBGE. 2001. Censo Demográfico 2000. Características da população e dos domicílios: resultados do universo. IBGE, Rio de Janeiro, 655p. 
Klein, A.H.F.; Santana, G.G.; Diehl, F.L.; Menezes, J.T. 2003. Analysis of hazards associated with sea bathing: results of five years work in oceanic beaches of Santa Catarina state, southern Brazil. Journal of Coastal Research. 35 (SI): 107-116.

Noernberg, M.A.; Lautert, L.F.C.; Araújo, A.D. \& Odresky, L.L. 1997. Base de dados digital do litoral paranaense em sistema de informações geográficas. Nerítica. 20(1): 67-82.

Noernberg, M.A. 2001. Processos morfodinâmicos no complexo estuarino de Paranaguá, Paraná, Brasil: um estudo a partir de dados in situ e Landsat-TM. Tese de Doutorado. Universidade Federal do Paraná - UFPR. 127p.

Noernberg, M.A.; Lautert, L.F.C.; Araújo, A.D.; Marone, E.; Angelotti, R.; Netto JR., J.P.B. \& Krug, L.A. 2006. Remote Sensing and GIS Integration for Modeling the Paranaguá Estuarine Complex, Brazil. Journal of Coastal Research. 39 (SI):1627-1631.

Polinari, M. 2000. Praias: ambientes social e dimensionalmente gerados em Pontal do Sul. Tese de Doutorado. Universidade Federal do Paraná UFPR. 195p.

Portobrás. 1983. Campanha de medições de ondas em Paranaguá, Paraná: período 21.08.1982 a 21.01.1983. INPH - DIDELE, Rio de Janeiro, $23 \mathrm{p}$.

Short, A.D.; Hogan, C.L. 1990. Sydney's southern surfing beaches: characteristics and hazards. In: FABBRI, P. (ed.). Recreational uses of coastal areas. Kluwer Sydney. 199-210 pp.

Submetido: Março/2009

Revisado: Maio/2009

Aceito: Fevereiro/2010 